кисть почки. Одной из причин отцасти явльется редкость поодобных случаев, В связи с чем они уходыт из поля диагностического нышения врача.

Mh не хотим говорить и о лечении-оно вытекает в каждом отдельном случае из размеров кисты, наличия или отсутствия нагноения, фунжции данной почки и т. д. Отметим только, что если при полиқистозндх поцках, которые чале всего бывают двусторонним, весьма важно беречь почечную паренхиму, т. к. бывагот случаи сыерти при явленилх уреми (Mikaniewscki видел сисрть при уцалении таких пощек в $30^{\circ} \%$ сл.),- то нам кажется, что при сонитарнңх гистах, нукно всенда стремиться удалить кисту.

Из хирург, пропедевт. клиники Ростовского гос. мед. институтая при ценгр. гор. больиице г. Ростов-на-дону (директор проф. Б. З. Гутников).

\title{
Ostitis fibrosa cystica localisata.
}

\section{3. И. Кечек.}

Патолого-анатомический сущностью ostitis fibrosa cystica является: I) замещсние жироного и клеточного костного мозга волокнистой соединительной тканью; 2) разрушение костной ткапи путем лакупарного всасывания; 3) метапластическое, а отчасти и остеобластическое образование новой остеондной и костной тқани; 4) опухолеподобные разрастания фиброзной, a также гигантокеточной ткани, напоминающей гиганто-клетолные саркомы и 5) образование в разросшейся соединительной ткани кисты.

Некоторые авторы, в том хисле и Recklinghausen, сцитают разрастание соедипительной ткани в костіом мозуу и әндосте первинным моментом, нсе же остальные моменты дистрофии костной ткани-вторицными.

Причину разрастання соединительной ткани они усматрињают в хроническом вослалсни, почему зто заболсвание и получило такое иазвание. Авторы из школы Іиика утверждагот, что изменения в костиои субстанции в виде обеднения ее изнестью и остальные проявления дистрофии не могут быть обцяснепы лишь как следствие фиброзного превращения костного мозга.

Они считают дистрофию костной ткани основным изменением, а разрастание соединитлынй ткани и побочные явления, в виде опухоли и кист, последовательным процессом. Поэтому указанные авторы из этих соображсиий решили заменить термин ostitis fibrosa другим названием osteodystropinia fibrosa, что и совпадает с давницним предложением Микулича.

Вопрос об әтиологии зтого заболевапия до сих пор не выяснен. Некоторые аиторы, жак Recklinghausen, рассматривают фиброзный остит как хропический воспалительный процесс, дру- 
гие же авторы (Phemister, Gordon и др.) находили уже в кистах kостей streptococcus viridans и динлококк. В данный момент әти теории оставлены, и на смену им появились лругие теории.

Њольшинство авторов (Benecke, Pommero, Haberer н др.) считает, чүо причиной образовапия кист в костях является травма, н онк обосновывают это ма том факте, что в костях в области травмы образуются множественные кровоизлияния, которые в дальнейшем и дают образование фиброзного остиэа. Травма в молодом возрасте имеет место чрезвьцайно часто, но заболевают только люди, имеющие предрасположение. Но другис авторы (Lехет, Lotscha), оснонываясь на экспериментальных данных, отрицают значение транмы в образовании кист в костях. Есть авторы, как Stenholm, қоторые полагағт, что в основе фиброзного остита лежит нарушение питания костного мозуа, вследствие сосудистых изменсний, за которыми следует атрофия паренхимы костного мозга и разрастание соединительIой ткани.

Го мпгпию Раппопорта, основываюцелося на „нервной теории“ Грекова, которой соответствуют следующие клинические явления: а) упорные боли невралгического характера в месте будупего перелома, и б) почти полная безболезненность самопроизвольных переломов,- Можио при фиброзных оститах говорить о неврите, поскольку имслтся слойкие локализованнде явления раздражения нервов.

Суцествует также и эндокринная теория. Сторонники этой теории рассматривают дистрофню костной субстанции, как нарушение известкового обмена, а последнее они станят в зависимость от расстройства функщии эндокринных желез (паращитовидыых желез). I laffheinz нашел из 45 случаев фнброзного остита п 20 случаях увеличенные эпнтелиальные тельца, а Marescha из 17 случаев-в шести.

Mandl и Gordoп произвели операции удаления увеличенных элителиальных телеп при кистах костей, после чсго значительно понизилось выделение Са, и киста постеленно заменилась костной юканью. Другие же анторы, наоборот, считают, что удаление эпителиальных телец не ичрает никакой роли в выделении Са и в обелнении нм кости.

Диагностика фиброзного остита в ряде случаев встречает трудлости.

Только рентен зиачительио облегчил эту задачу. Слицком уже нерезки и неопределенны начальные симптомы трактуемого нами заболевания. Они настолько нерсзки, что больной не обращает ңа них внимапия. Первые признаки, которые заставльют болынго обратиться к врачу,-әто болн в области образования кисты и иногда пољвление плотной ошухоли.

Кисты быеают одно-і многокамерные, достигают больцих размеров и истончают компактнңй слой кости до степени тонкости листа.

Чаще всего кисты располагаются в метафизарной части ґостей. 
Большинство авторов сводит лечение $k$ onеративному, радн кальному резекции пораженной кости в пределах здоровой ткани, с заполнением дефекта костным штифтом; иногда же 1 роводится консернативное олеративное леченис, заключаюееся в выскабливљнии кисты с последуюпей имплаптацией в образованную полость автолластинеского штифта. Некоторые авторы применяют просто ныскабливание костной кистозной полости.

Из упомянутых способов необходимо отдать предпочтение более радикальным, так как остеохондритические кистозные Полости обладағот известной активной склонностью к рецидиву, Это вндно из репидивов, наступавших у тех больных, которым вместо того или другого оперативного лечения, просто перела4hвали кость на месте образования кистл, предоставляя гости в дальнейем срастаться (часто в неправнльно положснии).

Үак, Коліg'у в течение 5 лет пришлось 4 раза подвергать перелому конечность боныного из-за рецидивировавшей кисты. Fanconnet проделал то же самое два paза на своси больном.

Такое рециливирование костных иист и плохая регенерация кости на месте перелома побуждали ряд авторов (Ралпопорт и др.) облучать после операции коненность рентгеном с дачей внутрь прспаратов кальция и других вепесль, повынаюиих костеобразовательную способность.

Лечение рекомендуется по возможности в молодом возрасте. Motoles из 45 случаев выскабливания кнст вставлял в 42 штифт, взятый из большеберцовой кости и установил, что у молодых субьектов, у которьх развитие костей еге не остановилось, перестройка трансллантата происходия сравнительно быстро, 39 - 10 месяцен. У больных свнше 24-летнего возраста для этого требуется 2 --3 года.

Перехожу к описанию трех случасн этоло редыого заболевания, іронедиих через нашу клинику. Двое больных подверглись оператквному лечению, а трстий обследован анбулаторно.

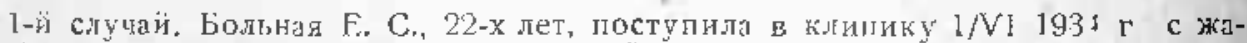

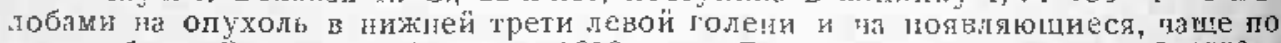
ночам, боли. Впервыс заболела в 1919 гопу Лсчилась от ревматизма. С $1920 \mathrm{r}$. лєчилась в туберкулезном отделении полтора года; тринимала иодислый қалий, ¿ в 1932 году подверглась, повидимому, алтильетическому лечению вливанием в вену и инъекциями в ягодичную об.тасть.

Все эти мсропрнятия но словам больиой пе дали результата.

На левой голени в области нижней ее трети с наружной стороны имеется огухоль костиой консистенции. На регтеновском снимке обнаружена киста малоберцовой кости. $7 / \mathrm{Vl}$-операцня. Кость, пораженная кистой, поднадкостничн улалена е пределах здоровой коси, и рана была зашнта наглухо. $27 \mathrm{NI}$ была вынисана в хорошем состояни. Іистологцческий диагноз: фиброзный остит с разрастанием грануляционой ткани, с обилием в ней гигатских кдегок (рис. 1 и 2).

2-ї стучй. Н К., 13 лет, поступил в клинику с жалобами ил боли в правом локтевом суставе с ограничением движений в нем. В январе 1935 года был ушиб правого локтевоге сустава; посте ушкба в области сустава стала расти опухоль, 4/IV-повторный ушиб того же локтевого сустава. Изеюцаяся опухоль на суставе после вторичного ушиба стала быстро расти; боли усилилнсь, и двнжения в сусаве стали огрнничены.

їравое элсчо атрофировано по сравнению с левым. В области правого локтевого сустава иа предплечье, на задней поверхиости имеется плотная костной 
жонсисгеция онухоль с ґлдкой поверхносьь, нелодвижна, безболезненная nа огухоли в области всего локтевого сустав заметны расширенные подкож-

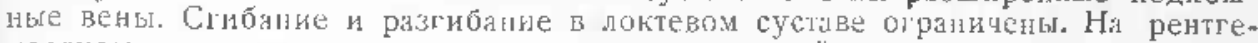

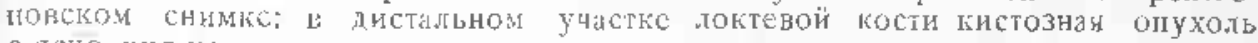

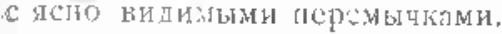

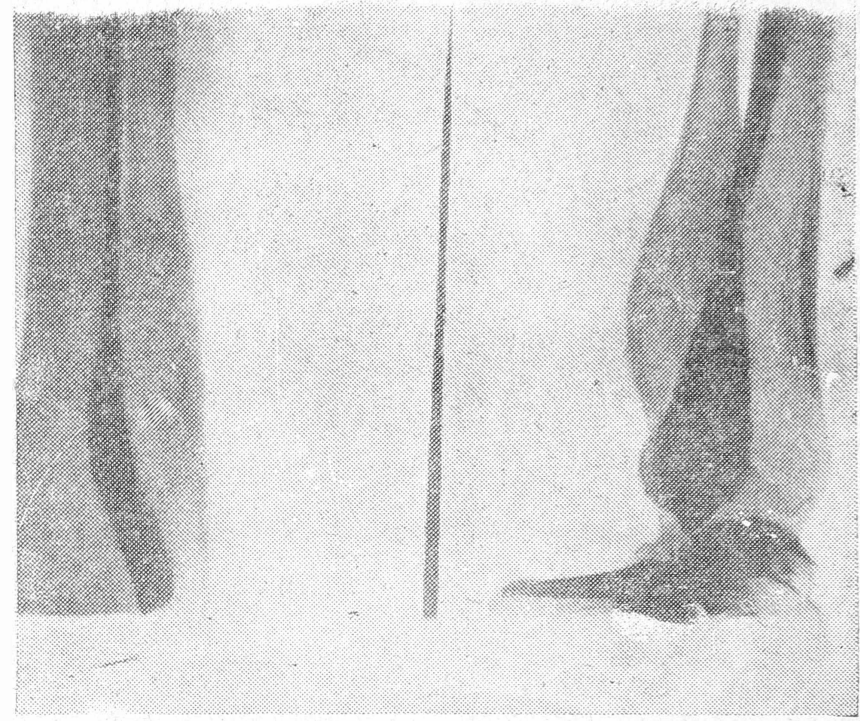

Рис. 1. 1-лї случай, Евгения С., 22 лет, до опсрации.

Реакция Касони отрицательная. $27 / \mathrm{V}$-операция под общим пркозом. ІІроксимальный отдел локтевой кости представияет кистозную веретенообразно

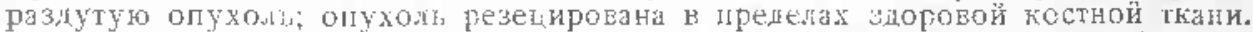

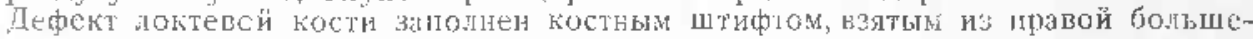

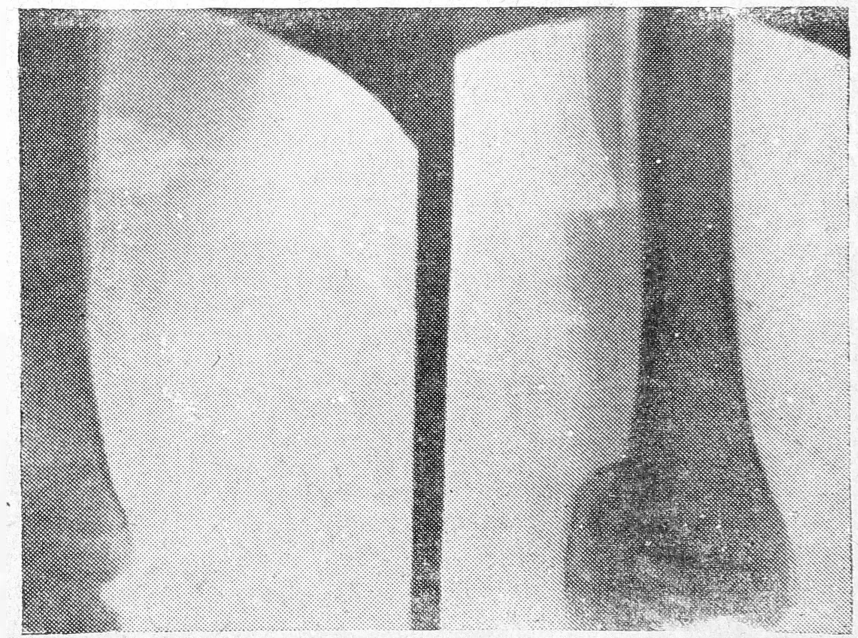

Рис. 2. Евгения С, 22 лст, постс операцши. 


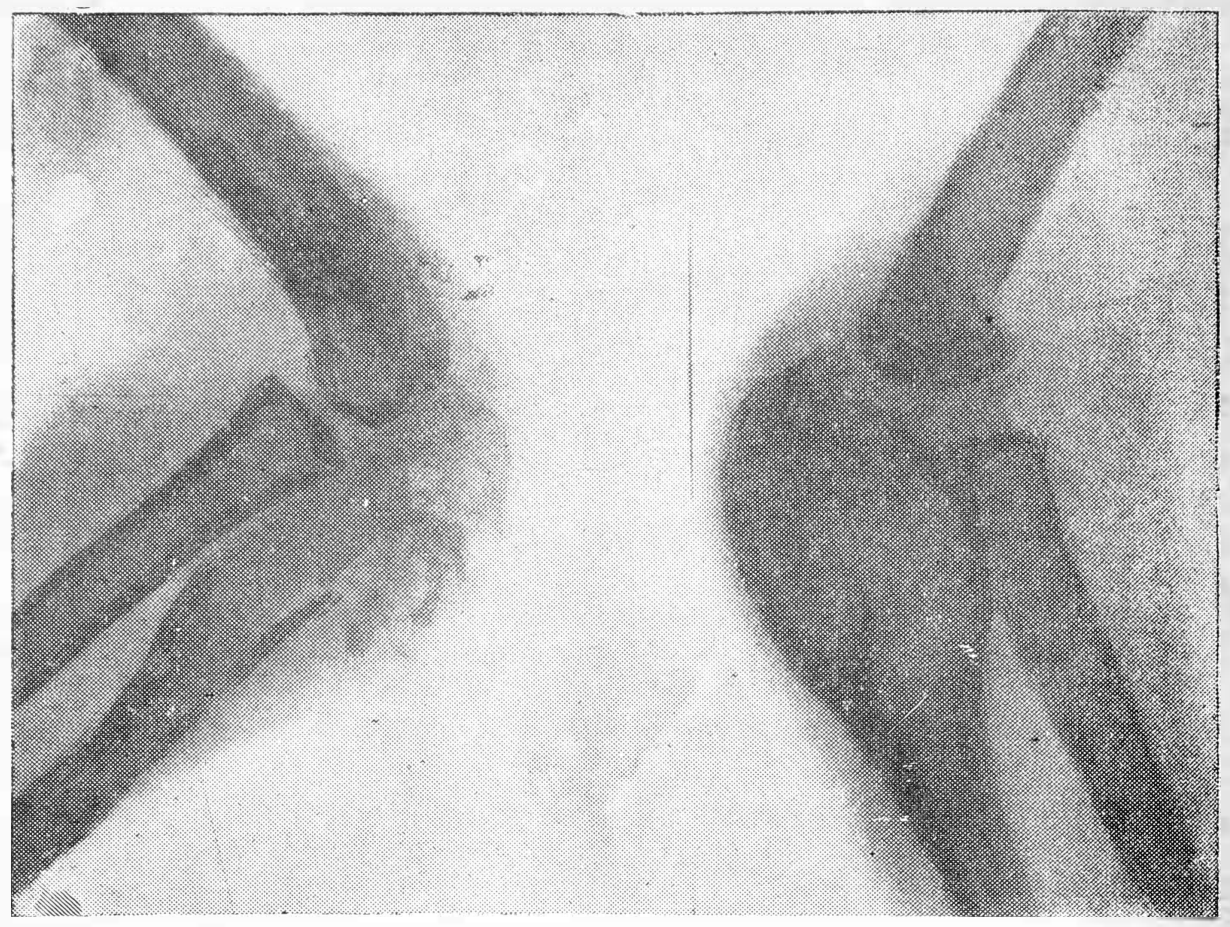

Рис. 3. 2-й случай. Ннколай К., 13 лет, до операции.

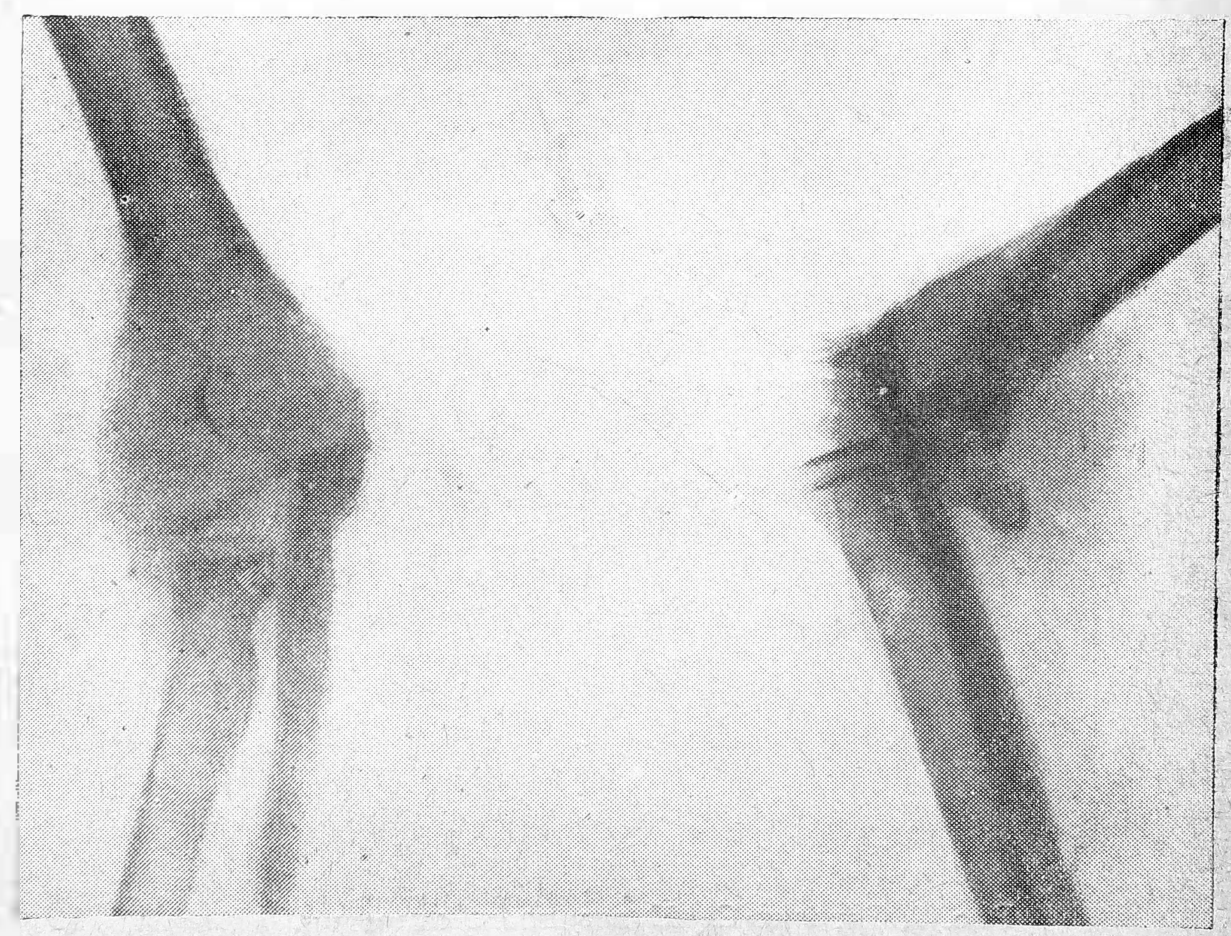

Рис. 4. Николай К., 13 лет, после операции. 
берцовой кости, 8 см длиною, $1 \frac{1}{2}$ см в поперетиике. Операпиония рана на предллечье и голени зашита наглухо. Гилсовая повязка на всю руку. Локтевой сустав в положении сгибания под углом в $90^{\circ}$. На 17-й день после операции выписан в типсовой ловязке $\mathrm{c}$ нормальной темлературой и в хорошем состоянии. Гистологический диагноз: фиброзный остит.

Чепез шесть месяцев у больного в области трапсплантировауного хцтифта констатировала плотная костная мозоль и полиый объем движения в поктевом сочленении (рис. 3 и 4).

3-й случай, амбулаторный, H. E, 36 лет, постуиил в сентябре 1926 года. Заболел зимой 1935 года, когда после элления почувствовал боль в области левого бедра, в пижией трети. В мае 1935 года вторичю улал, после тего появиласл припухлость.

Рентгеновские снимки изменепий не обнаружили. В 1936 году больнй снова ушиб ногу и после этого вторично была произедена ренгенография уже в нашей больнице. На снимке была обнаружена киста в нижнсй трети бедра.

Ha передне-наружной поверхности в нижней трети левого бедра прощупывается опухоль твердой консистеции, безболељенная.

На основания щриведенных случаев мы можем сделать выводы как в отношении оперативного лечения фиброзного остита, так и в отношении некоторых моментов, быть может, играющих роль в происхождении этого заболевания.

В анамнезе всех наших больных имела место травма, иногда повторная, следовательно травму можно считать фактором, влияющим в определенных случаях на развитие заболевания.

Что касается лечения, то необходињо предпочесть радикальное вмешательство ввиде резекции поражелного участка ности в иределах здоровых тыаней с автопластической имплантацией в дефект соответствующей толицны костного штифта. 